\title{
Salvia bowleyana Dunn root is a novel source of salvianolic acid B and displays antitumor effects against gastric cancer cells
}

\author{
BINGHUA CHEN $^{1 *}, \mathrm{CHAOQUN} \mathrm{HUANG}^{1,2^{*}}$, YUANYAN ZHANG $^{1}$, \\ XIAOQIONG TANG ${ }^{1}$, SUHUAN LI ${ }^{1}$, QINGSHUI WANG ${ }^{1}$ and YAO LIN ${ }^{1}$ \\ ${ }^{1}$ College of Life Sciences, Fujian Normal University, Fuzhou, Fujian 350117; \\ ${ }^{2}$ Central Laboratory, The Fifth Hospital of Xiamen, Xiamen, Fujian 361101, P.R. China
}

Received July 30, 2019; Accepted April 3, 2020

DOI: $10.3892 / 01.2020 .11611$

\begin{abstract}
Salvianolic acid B (Sal-B) is widely used in China for the treatment of numerous diseases. Currently, Salvia miltiorrhiza Bunge is the main source of this compound, but Salvia bowleyana Dunn, a surrogate of S. miltiorrhiza Bge, may provide a novel source for obtaining more Sal-B. In the present study, a simple method for separation and purification of phenolic compounds from S. bowleyana Dunn roots was employed. Sal-B was subsequently purified and its inhibitory effect on the gastric cancer HGC-27 and AGS cell lines was investigated. Sal-B extracted from S. bowleyana Dunn displayed significant antitumor activity in proliferation and apoptosis assays. Overall, it was found that $S$. bowleyana Dunn has a higher Sal-B content than S. miltiorrhiza Bge and may be used as a novel source of this potential anti-gastric cancer compound.
\end{abstract}

\section{Introduction}

Salvianolic acid B (Sal-B) is a water-soluble component of Salvia miltiorrhiza Bunge with a wide spectrum of effects, including anti-inflammatory effects, inhibition of new vessel formation and atherogenesis, and relief of chronic hepatitis and liver fibrosis, as well as antioxidant and tumor-modulating effects (1-4). A previous study demonstrated that this compound inhibits cell proliferation in head and neck squamous cell carcinoma (5). In addition, it has been reported to decrease viability of U87 cells in a dose- and time-dependent manner (6).

S. miltiorrhiza Bge is the main source of Sal-B (7-10) and it also possesses another active ingredient, tanshinone, that

Correspondence to: Professor Yao Lin, College of Life Sciences, Fujian Normal University, 1 Technology Road, Fuzhou, Fujian 350117, P.R. China

E-mail: yaolin@fjnu.edu.cn

${ }^{*}$ Contributed equally

Key words: Salvia miltiorrhiza Bunge, salvianolic acid B, Salvia bowleyana Dunn, gastric cancer is widely used clinically. Tanshinone has been reported to inhibit oxidation of low-density lipoproteins, improve lipid metabolism, protect endothelial cells and prevent myocardial ischemia (11-13). In addition, this compound displays preventive effects on cardiovascular diseases, such as atherosclerosis, and reduces the area of myocardial infarction and the oxygen consumption of the myocardium (14-17). Unfortunately, the current extraction methods of Sal-B result in the loss of fat-soluble tanshinone. Following tanshinone extraction, the residue can be used for Sal-B extraction by process modification; however, the yield is low and the process is time-consuming and laborious (18). Therefore, S. miltiorrhiza Bge is mainly used in the extraction of tanshinone rather than Sal-B. However, S. miltiorrhiza Bge is very expensive, and its accessibility is limited due to its regional distribution. It is therefore imperative to look for alternative sources of Sal-B to replace S. miltiorrhiza Bge. In this regard, Salvia bowleyana Dunn has been suggested as an alternative source since it is often used as a surrogate of S. miltiorrhiza Bge. This species is abundant in areas that exhibit high incidences of gastric cancer in China, such as Fujian (19).

In the present study, the water-soluble components of S. miltiorrhiza Bge and S. bowleyana Dunn were extracted and assayed for antitumor effects on gastric cancer cell lines. Since there have only been a few studies on Sal-B for the prevention and treatment of gastric cancer (2,20-23), the present study aimed to explore the potential of these species in treating gastric cancer.

\section{Materials and methods}

Determination of Sal-B in S. bowleyana Dunn roots. $S$. bowleyana Dunn plants were collected from Lianjiang (Fuzhou, China) in July 2014 (E, 119 20'; N, 20¹1'; Alt, 57 m), while S. miltiorrhiza Bge (produced in Anhui, China, in 2015) was purchased from Hui Chun Pharmacy (Fuzhou, China). The roots of S. bowleyana Dunn and S. miltiorrhiza Bge were washed, dried, ground to a fine powder and passed through a $425-\mu \mathrm{m}$ sieve respectively. Sal-B in the roots of the two plants was purified by the following experimental steps. A total of $1 \mathrm{~g}$ of the resulting powder was placed in an Erlenmeyer flask with $20 \mathrm{ml} 60 \%$ ethanol and left at room temperature. The rest of the powder was stored at $\leq-20^{\circ} \mathrm{C}$ for subsequent use. 
After 6-8 h, the solution was exposed to ultrasound at $40 \mathrm{kHz}$ for $\sim 35 \mathrm{~min}$ and centrifuged for $15 \mathrm{~min}$ at $8,000 \mathrm{x} \mathrm{g}$, and the supernatant was collected at room temperature. Subsequently, $20 \mathrm{ml} \mathrm{60 \%} \mathrm{ethanol} \mathrm{was} \mathrm{added} \mathrm{to} \mathrm{the} \mathrm{Erlenmeyer} \mathrm{flask,} \mathrm{and} \mathrm{the}$ solution was exposed to ultrasound at $40 \mathrm{kHz}$ for $35 \mathrm{~min}$ and centrifuged at $8,000 \mathrm{x} \mathrm{g}$ for $15 \mathrm{~min}$ at room temperature. The resultant supernatant was collected and mixed with the supernatant collected in the first phase. Finally, the supernatant was topped up to $1,000 \mathrm{ml}$ using ultra-pure water and stored at $4^{\circ} \mathrm{C}$ for use in subsequent experiments.

The extract was analyzed using Waters 2695 Alliance HPLC high-performance liquid chromatography (Waters Corporation). A Sal-B standard sample ( $\geq 98.3 \%$ ) was purchased from Nanjing Chunqiu Biological Engineering Co., Ltd., and was used for analysis on ZORBAX Eclipse XDB-C18 $(4.6 \times 250 \mathrm{~mm}, 5 \mu \mathrm{m})$ chromatography columns (Agilent Technologies, Inc.). The $(4.6 \times 250 \mathrm{~mm})$ are the diameter and length of the column, respectively. The particle size of the particles is $5 \mu \mathrm{m}$ in the column, which is the composition of the solid phase. Results were detected using the Ultrospec ${ }^{\mathrm{TM}}$ 2100 pro UV-Vis variable wavelength detector (Amersham; Cytiva) at a wavelength of $286 \mathrm{~nm}$. The analysis involved a mobile phase with $0.5 \%$ carboxylic acid, $99.9 \%$ acetonitrile and $99.9 \%$ methanol in the ratio 48:7:45 (V:V:V). Other conditions included a $0.8-\mathrm{ml} / \mathrm{min}$ flow rate and a column temperature of $28^{\circ} \mathrm{C}$ for a sample volume of $10 \mu \mathrm{l}$. The analyzed Sal-B contents were imaged and quantified using Empower System Suitability (24-26). Sal-B in S. miltiorrhiza Bge root was not used in the remaining experiments

Purification and verification of Sal-B. A 20-g sample of powder from S. bowleyana Dunn roots was used in the extraction of plant components as aforementioned. The obtained supernatant was concentrated under reduced pressure at $45^{\circ} \mathrm{C}$ for ethanol removal, and the solution was subsequently diluted to $500 \mathrm{ml}$ with ultra-pure water and divided into 10 bottles (500 ml/bottle). A total of $4 \mathrm{~g} \mathrm{X}-5$ resin (Nankai University Chemical Plant) was added into each bottle, followed by $12 \mathrm{~h}$ of shaking at $110 \mathrm{r} \mathrm{min}^{-1}$ in a rotary incubator at room temperature to allow full absorption of the compound by the resin. Subsequently, any resin impurities on the surface were washed off by running water, and the rest of the solution in the bottle was discarded. The mixture absorbed by the resin was eluted using $60 \%$ ethanol and shaken for $1-2 \mathrm{~h}$ at $110 \mathrm{r} \mathrm{min}^{-1}$ in a rotary incubator at room temperature until the resin became colorless. The ethanol solution was concentrated under reduced pressure and freeze-dried to obtain a powder. The powder was dissolved in $10 \%$ ethanol solution and filtered using a $0.45 \mu \mathrm{m}$ microporous membrane. Subsequently, the filtered solution was purified via column chromatography. Sephadex LH-20 (Amersham; Cytiva) was used for chromatographic media in the columns $(\Phi 1.6 \times 70 \mathrm{~cm})$ and ethanol solutions of different volume percentages $(10,30$ and $50 \%)$ were used for eluting the columns in sequence. Finally, the solution was concentrated to dryness in a rotary evaporator under reduced pressure conditions, and the yield was calculated. The purified compound powder was stored at $-20^{\circ} \mathrm{C}$ before HPLC and nuclear magnetic resonance (NMR) analyses.

A total of $2 \mathrm{mg}$ of the powder was dissolved in $2 \mathrm{ml}$ methanol, and the filtered sterile solution was placed into a sample bottle. Components of this purified powder were identified by liquid chromatography-mass spectrometry (LC-MS) and liquid chromatography-tandem mass spectrometry (LC-MS ${ }^{2}$ ) using the aforementioned HPLC chromatographic conditions. Parameters for mass spectrometry (G6520B; Agilent Technologies, Inc.) were as follows: A negative ionization mode, fragmentor set at $100 \mathrm{~V}$, mass spectra scanning range of $200-1,200 \mathrm{~m} / \mathrm{z}$, a two-stage mass spectrometry scanning range of $50-800 \mathrm{~m} / \mathrm{z}$, nebulizer pressure $40 \mathrm{psi}(10 \mathrm{l} / \mathrm{min})$, nitrogen gas temperature of $350^{\circ} \mathrm{C}$ and the energy of collision chamber of 10,20 and $40 \mathrm{eV}(27,28)$. A total of $8 \mathrm{mg}$ powder was obtained and dissolved in $0.7 \mathrm{ml} \mathrm{D}_{2} \mathrm{O}$ by ultrasound in a $1-\mathrm{ml}$ clean centrifugal tube for ${ }^{1} \mathrm{H}$ NMR test using the UNITY-400 NMR spectrometer (Varian).

Establishment of cell culture. The human gastric cancer HGC-27 and AGS cell lines were obtained from The Cell Bank of Type Culture Collection of the Chinese Academy of Sciences for use in the present study. All cells were tested by short tandem repeat genotyping and confirmed to be mycoplasma negative. HGC-27 cells were grown in RPMI-1640 medium, whereas AGS cells were maintained in DMEM F12 (both Biological Industries). The cultures were supplemented with $10 \%$ FBS (Biological Industries), $100 \mathrm{U} / \mathrm{ml}$ penicillin $\mathrm{G}$ and $100 \mu \mathrm{g} / \mathrm{ml}$ streptomycin (BBI Life Sciences Corporation). All cells were grown at $37^{\circ} \mathrm{C}$ in a humidified incubator containing $5 \% \mathrm{CO}_{2}$.

Sulforhodamine B (SRB) assay. Cells (100 $\mu \mathrm{l})$ were seeded into 96-well plates at concentrations of 10,000 and 8,000 cells/well for AGS and HGC-27, respectively. After $24 \mathrm{~h}$ of incubation, the gastric cancer cells were treated with different concentrations of Sal-B $(100,200,400,600$ and $800 \mu \mathrm{M})$ for $48 \mathrm{~h}$ at $37^{\circ} \mathrm{C}$. The culture media was removed, cells were fixed with $3 \%$ trichloroacetic acid and stained with $0.057 \%$ SRB (both Sigma-Aldrich; Merck KGaA) (29). SRB was solubilized in $10 \mathrm{mM}$ Tris base solution, and its fluorescence was quantified using the Synergy HT Multi-Mode Microplate Reader (Agilent Technologies, Inc.) at a wavelength of $510 \mathrm{~nm}$. The wells treated with Sal-B were compared with control wells $(30,31)$. At least three biological replicates were performed for each assay.

Cell Counting Kit-8 (CCK-8) assay. Cells (100 $\mu \mathrm{l})$ were seeded into 96-well plates at concentrations of 10,000 and 8,000 cells/well for AGS and HGC-27, respectively. After $24 \mathrm{~h}$, the gastric cancer cells were treated with different concentrations of Sal-B as described for the SRB assay for $48 \mathrm{~h}$ at $37^{\circ} \mathrm{C}$. After treatment, $10 \mu \mathrm{lCCK}-8$ solution (TransGen Biotech Co., Ltd.) was added to each well, according to the manufacturer's protocol, and the cells were incubated at $37^{\circ} \mathrm{C}$ for $2 \mathrm{~h}$. Subsequently, optical density values were measured at $450 \mathrm{~nm}$ using the Synergy HT Multi-Mode Microplate Reader. Drug-treated wells were compared with solvent-controlled wells using results obtained from three independent experiments.

Colony formation assay. The ability of cells to form colonies was analyzed for HGC-27 and AGS cells in the exponential phase. Each cell line was divided into 3 groups with 3 replicate 
A
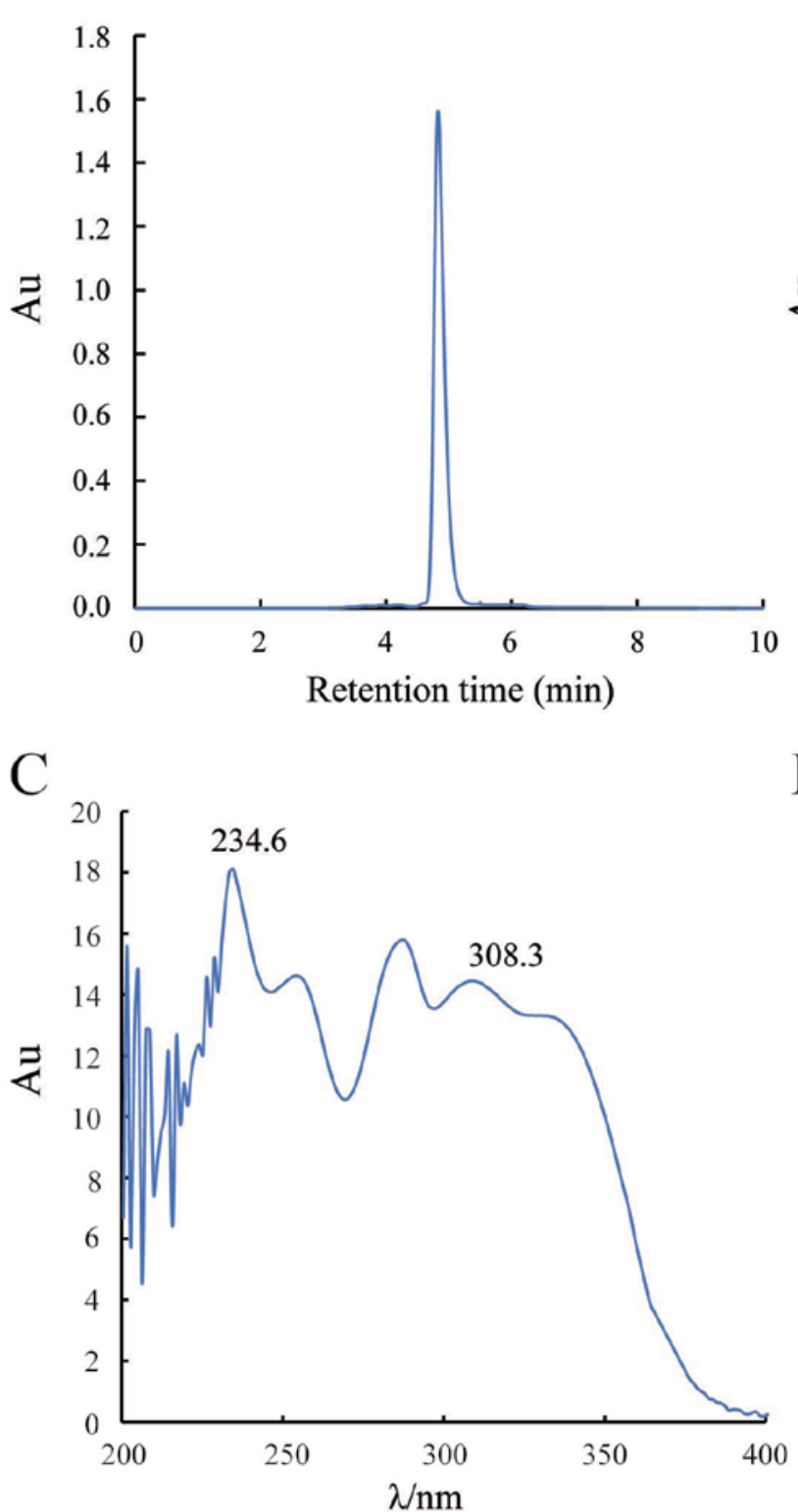

B

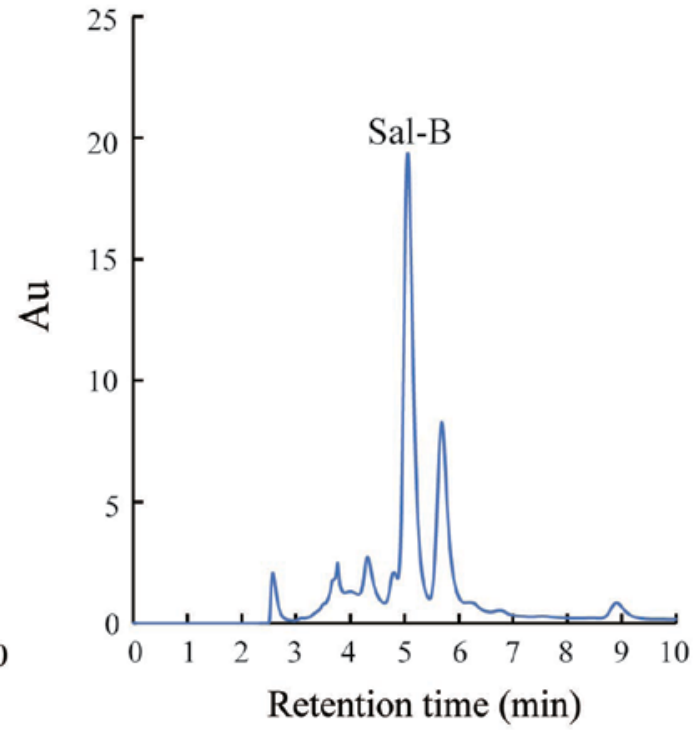

D

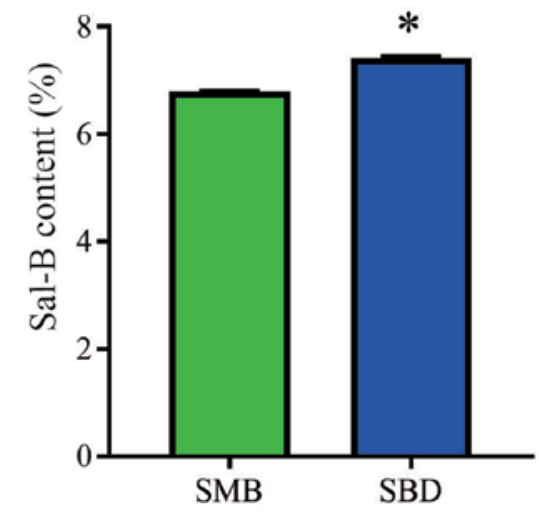

Figure 1. Sal-B content in SBD and SMB roots. (A) Standard sample of Sal-B analyzed via HPLC. (B) Chromatogram and (C) UV spectrum of HPLC registered with a diode array detector at $286 \mathrm{~nm}$ for $\mathrm{SBD}$ root. (D) Quantification of Sal-B content. Data are shown as the mean \pm SEM ( $\mathrm{n}=3$ ). ${ }^{*} \mathrm{P}<0.05 \mathrm{vs.} \mathrm{SMB}$. Sal-B, salvianolic acid B; HPLC, high-performance liquid chromatography; SMB, Salvia miltiorrhiza Bunge; SBD, Salvia bowleyana Dunn.

wells in each group and seeded into 6 -well plates (1x107/well), and were subsequently treated with 0,400 or $800 \mu \mathrm{M}$ Sal-B when the monolayer cell density reached $70 \%$ confluency. After $48 \mathrm{~h}$, adhered cells were disassociated with trypsin and cells from each well were seeded into 6-well plates. Additionally, 500 cells/well of AGS and HGC-27 were seeded to continue culture in complete medium without Sal-B treatment. The cells were grown for 7 to 14 days to allow colony formation from viable clonogenic cells. After culture, the medium was removed, and $70 \%$ methanol was added to fix the cells for $15 \mathrm{~min}$, then methanol was discarded and stained with 5\% Giemsa (Sigma-Aldrich; Merck KGaA) for 10 min after air drying at room temperature. Subsequently, the plates were washed with PBS and captured to calculate colony numbers, using a Canon EOS 70D (https://www.canon.com.cn/product/70d). Statistical results were obtained from three independent experiments.
Protection from oxidative DNA damage induced by 2,2'-azobis (2-methylpropionamidine) dihydrochloride (AAPH). AAPH (Sigma-Aldrich; Merck KGaA) is an oxidizing agent, and its formation of cationic free radicals can occur at the first level. The ability of the extracted Sal-B to protect the supercoiled pUC18 plasmid from AAPH was measured according to the method previously described by Zhang and Omaye (32), with some modifications. Briefly, $2 \mu \mathrm{l}$ of intact pUC18 plasmid $(0.1 \mu \mathrm{g} / \mu \mathrm{l})$ was mixed with various concentrations $(0.017 \mathrm{mmol} / 1,0.03,0.06$ and $0.13 \mathrm{mmol} / \mathrm{l})$ of Sal-B samples $(7 \mu \mathrm{l})$ and $12.5 \mathrm{mM} \mathrm{AAPH}$ $(6 \mu 1)$ in PBS (pH 7.4), and then the mixture was incubated at $37^{\circ} \mathrm{C}$. After $1 \mathrm{~h}$ of incubation, the samples were electrophoresed on a $0.8 \%$ agarose gel for $30 \mathrm{~min}$ and subsequently stained for 3-5 min with $0.5 \mu \mathrm{g} / \mathrm{ml}$ ethidium bromide. Analysis of DNA damage was performed on images taken using a GelDoc EZ gel image analysis system (Bio-Rad Laboratories, Inc.) (33). 
Western blot analysis. Proteins were extracted from cells using RIPA buffer composed of $50 \mathrm{mM}$ Tris $\mathrm{HCl}(\mathrm{pH} \mathrm{8.0)}$, $150 \mathrm{mM} \mathrm{NaCl}, 1 \% \mathrm{NP}-40,0.5 \%$ sodium deoxycholate and $0.1 \%$ SDS. Protein concentration was measured using the Pierce BCA Protein assay kit (Thermo Fisher Scientific, Inc.), $30 \mu \mathrm{g}$ protein/lane separated via SDS-PAGE on a $10 \%$ gel and transferred to a nitrocellulose membrane (GE Healthcare Life Sciences). After blocking with 5\% skimmed milk powder for $1 \mathrm{~h}$ at room temperature, the nitrocellulose membrane was incubated with Caspase 3 mouse mAb (1:1,000; cat. no. 9668) and GAPDH rabbit mAb (1: 1,000; cat. no. 2118; both from Cell Signaling Technology, Inc.) overnight at $4^{\circ} \mathrm{C}$. Subsequently, the blots were stained with the IRDye ${ }^{\circledR} 680$ RD goat-anti-rabbit IgG (cat. no. 926-68071) and IRDye ${ }^{\circledR} 800 \mathrm{CW}$ goat anti-mouse IgG (cat. no. 926-32210; both 1:5,000 and from LI-COR Biosciences) secondary antibodies labeled with fluorescence in a cassette at room temperature for $1 \mathrm{~h}$. Subsequently, the blots were directly imaged and semi-quantified using the Odyssey Infrared Imaging system (model no. 9140; LI-COR Biosciences) (34).

Flow cytometry. Cells were seeded in 6-well plates at a density of $2 \times 10^{5}$ cells/well. After $24 \mathrm{~h}$, the cells were treated with Sal-B $(0,400$ and $800 \mu \mathrm{M})$ at $37^{\circ} \mathrm{C}$ for $48 \mathrm{~h}$ and assessed for cellular apoptosis using the AnnexinV-FITC/PI Apoptosis Detection kit (Beyotime Institute of Biotechnology) according to the manufacturer's protocol. Apoptotic cells were analyzed using a flow cytometer and FlowJo software (v10; FlowJo LLC).

Statistical analysis. Data were analyzed using one-way ANOVA with a Dunnett's post hoc test. Analyses were performed in GraphPad Prism v7 (GraphPad Software, Inc.). Data are presented as the mean \pm SEM. $\mathrm{P}<0.05$ was considered to indicate a statistically significant difference. $\mathrm{The} \mathrm{IC}_{50}$ value was calculated by Dr Fit 1.042 (35).

\section{Results}

S. bowleyana Dunn roots contain high Sal-B content. Analysis of the peak area of the standard sample resulting from HPLC as well as linear regression [y (peak area $\left.=9480.2 \times(\mathrm{mg} / \mathrm{ml})-181.39\left(\mathrm{R}^{2}=0.9998\right)\right]$ allowed detection of Sal-B in the extract (Fig. 1A). The content of Sal-B was imaged and quantified using Empower System Suitability (Fig. 1B and C). Quantification revealed a significantly higher Sal-B content in $S$. bowleyana Dunn roots (7.42\%) than in S. miltiorrhiza Bge root (6.79\%; $\mathrm{P}<0.05$; Fig. 1D). After purification, the yield of Sal-B was $4.26 \%$ and the purity of Sal-B was $93.26 \%$ by HPLC analysis.

Sal-B in S. bowleyana Dunn roots is verified by LC-MS and $L C-M S^{2}$. The purified component extracted from $S$. bowleyana Dunn roots was verified by LC-MS and LC-MS ${ }^{2}$. Separation and purification procedures allowed the identification of a substance with molecular formula $\mathrm{C}_{36} \mathrm{H}_{30} \mathrm{O}_{16}$ and molecular mass of 718. The compound can lose one proton to be negatively charged under the condition of negative ion full-wave scanning mass spectrometry. Thus, its base peak is the molecular ion peak and the $\mathrm{m} / \mathrm{z}$ value was 717.14 (Fig. 2A). Ion fragments of the compound from different collision energies were collected and detected, including those at $\mathrm{m} / \mathrm{z} 519,339,321$ and 295 (Fig. 2B-D). These fragments were consistent with the standard sample of Sal-B and with a previous report (36). The current results indicated that Sal-B was formed by condensation of lithospermic acid and danshensu, and that its two ester bonds were the most prone to breaking. Therefore, Sal-B is liable to lose two danshensu units and form two different $\mathrm{m} / \mathrm{z} 519$ substances (paths a and b; Fig. 2E). Subsequently, two substances, m/z 339 (paths $\mathrm{a}_{1}$ and $\mathrm{b}_{2}$ ) and $\mathrm{m} / \mathrm{z} 321$ (paths $\mathrm{a}_{2}$ and $\mathrm{b}_{1}$ ), are formed, with $\mathrm{m} / \mathrm{z} 339$ having two possible structures (Fig. 2E). The ion fragments of m/z 321 are formed by removing monomolecular danshensu. The ion fragments of the two $\mathrm{m} / \mathrm{z} 339$ structures can additionally form two different $\mathrm{m} / \mathrm{z} 321$ structures (paths $\mathrm{a}_{3}$ and $b_{3}$; Fig. 2E). The chemical structure of Sal-B was identified according to its ${ }^{1} \mathrm{H}$ NMR data. Compared with the data in the literature (9), the data of the compound was the following: ${ }^{1} \mathrm{H}$ NMR (400 MHz, D 2 ), ठ/ppm: 6.78 (m, 7 H; H 1), 6.63 (m, 2 H; H 2), 6.27 (d, J=8 Hz, 1 H; H3), 6.08 (d, J=2 Hz, 1 H; H 4), 5.92 (dd, 1 H; H 5), 5.80 (d, J=6 Hz, 1 H; H 6), 5.68 (d, J=16 Hz, 1 H; H 7), 4.85 (dd, 2 H; H 8), 4.75 (dd, 9 H; H 9), 4.09 (d, J=6 Hz, $1 \mathrm{H} ; \mathrm{H} 10), 2.97$ (dd, $1 \mathrm{H} ; \mathrm{H}$ 11), 2.80 (m, 2 H; H 12) and 2.41 (dd, $1 \mathrm{H}$; H 13) (the $\mathrm{H}$ number corresponds to the structure shown in Fig. 2F). The current results indicated that the purified product corresponded to Sal-B.

Sal-B effectively inhibits proliferation of gastric cancer cells. A number of biological experiments were conducted to examine the anti-gastric cancer effect of purified Sal-B extracted from S. bowleyana Dunn. Treating AGS and HGC-27 cells with different concentrations of purified Sal-B inhibited cell proliferation. This is based on the different $\mathrm{IC}_{50}$ values obtained from the SRB (AGS, $\sim 824 \mu \mathrm{M}$; HGC, $\sim 576 \mu \mathrm{M}$; Fig. 3A) and CCK-8 assays (AGS, $\sim 615 \mu \mathrm{M}$; HGC, $\sim 511 \mu \mathrm{M}$; Fig. 3B).

A colony formation assay comparing Sal-B-treated HGC-27 cells with control cells did not reveal significant differences (Fig. 4A and B). However, colony formation in AGS cells was strongly suppressed at 400 and $800 \mu \mathrm{M}$ (Fig. 4C and D). Western blot analysis of AGS and HGC-27 cells treated with varying concentrations of Sal-B revealed that the compound had a significant effect on the expression levels of cleaved caspase-3 only when treating HGC-27 cells with $800 \mu \mathrm{M}$ Sal-B (Fig. 5A-D). Alternative assessment of apoptosis using flow cytometry revealed similar results in AGS and HGC-27 cells (Fig. 5E-H).

Finally, the ability of Sal-B from S. bowleyana Dunn to prevent oxidative DNA damage was examined (Fig. 6). It was observed that oxidative DNA damage was gradually diminished with increasing Sal-B concentration. Oxidative DNA damage was rarely observed at $0.06 \mathrm{mmol} / 1 \mathrm{Sal}-\mathrm{B}$; this concentration may effectively prevent DNA from being sheared. To some extent, the low level of apoptosis may be associated with the protective effect of Sal-B on DNA.

\section{Discussion}

The molecular weight of purified monomeric compound extracted from $S$. bowleyana Dunn was successfully detected using HPLC-MS, while ion fragments were analyzed via HPLC-MS ${ }^{2}$. Results from ion fragments were consistent with the decomposition product of Sal-B, and Sal-B content from 
A

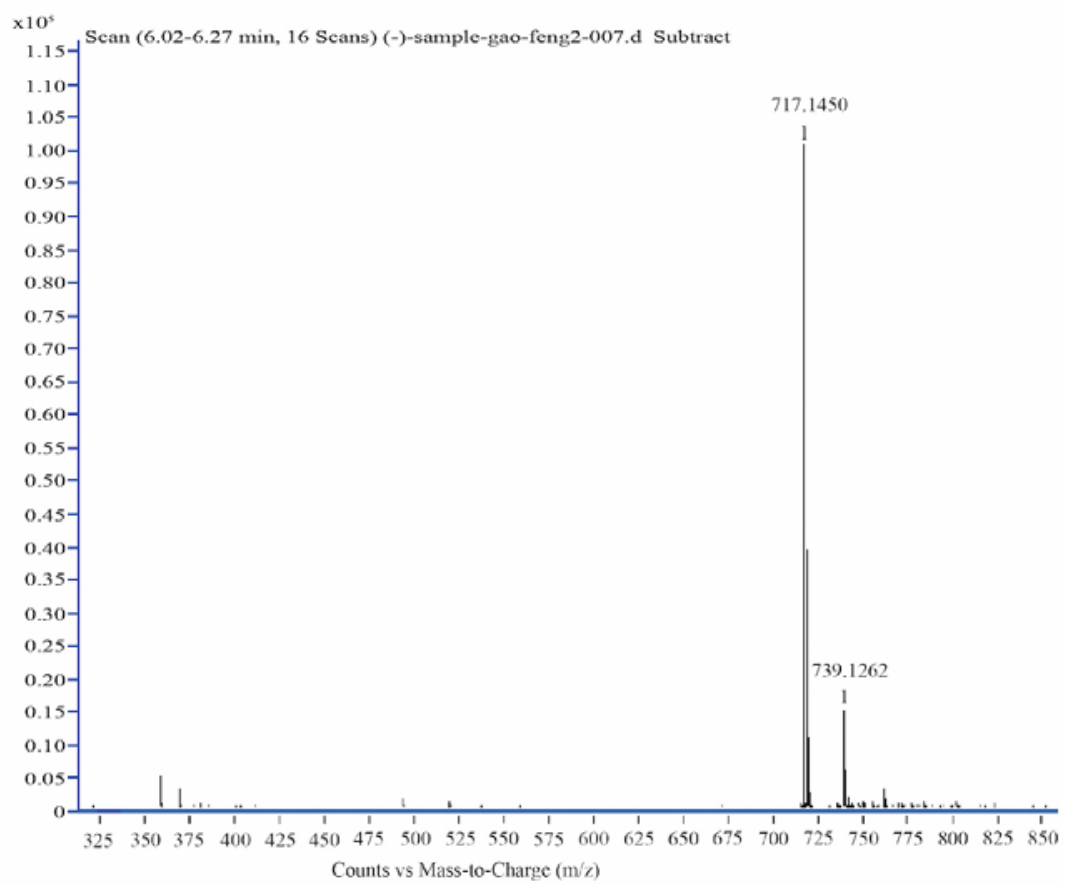

\section{B}
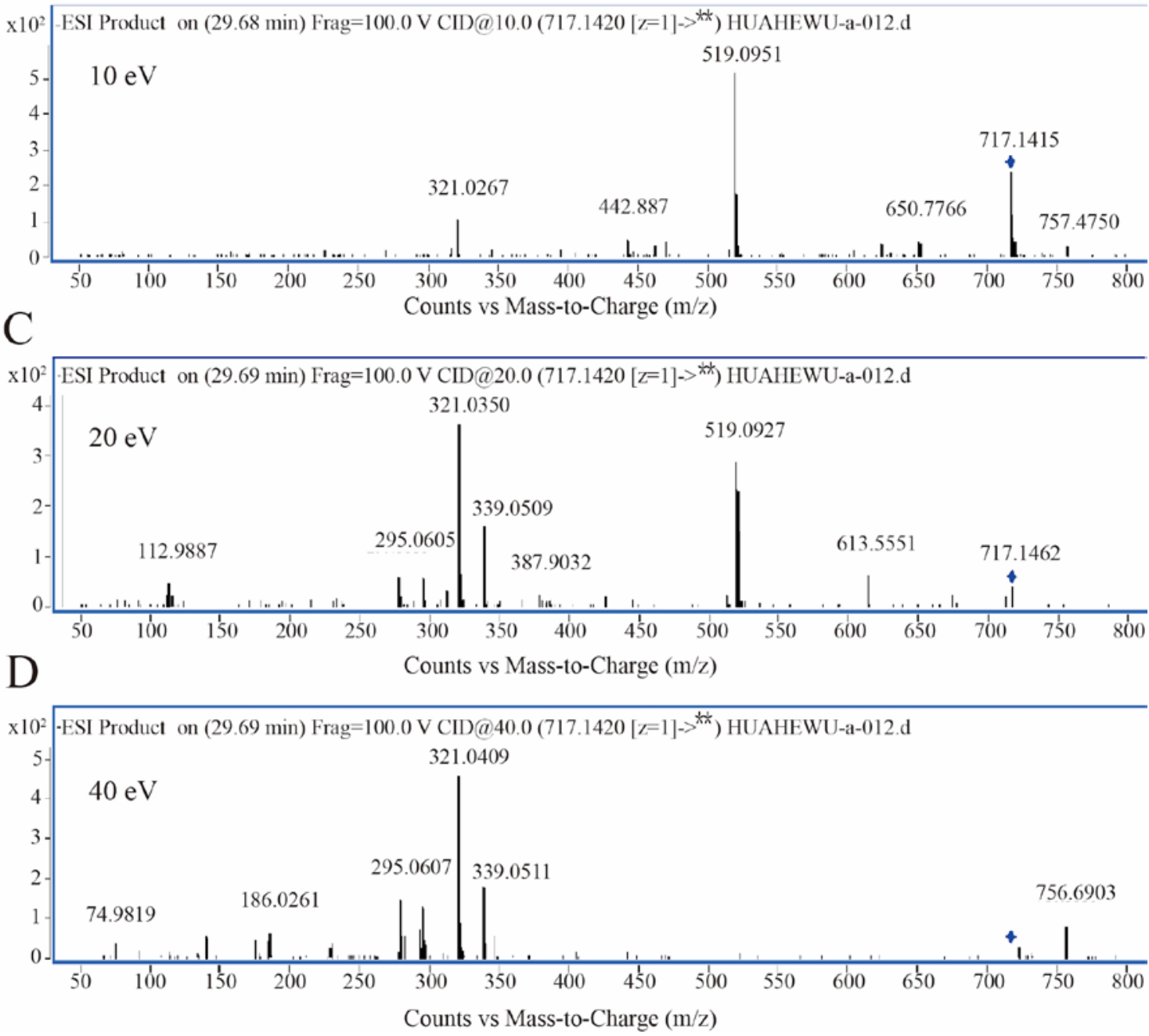

Figure 2. Sal-B identification via liquid chromatography-mass spectrometry, LC-MS ${ }^{2}$ and ${ }^{1} \mathrm{H}$ NMR spectrum. (A-D) Mass spectrum via negative ESI for Sal-B. LC-MS ${ }^{2}$, liquid chromatography-tandem mass spectrometry; NMR, nuclear magnetic resonance; ESI, electrospray ionization; Sal-B, salvianolic acid B. 

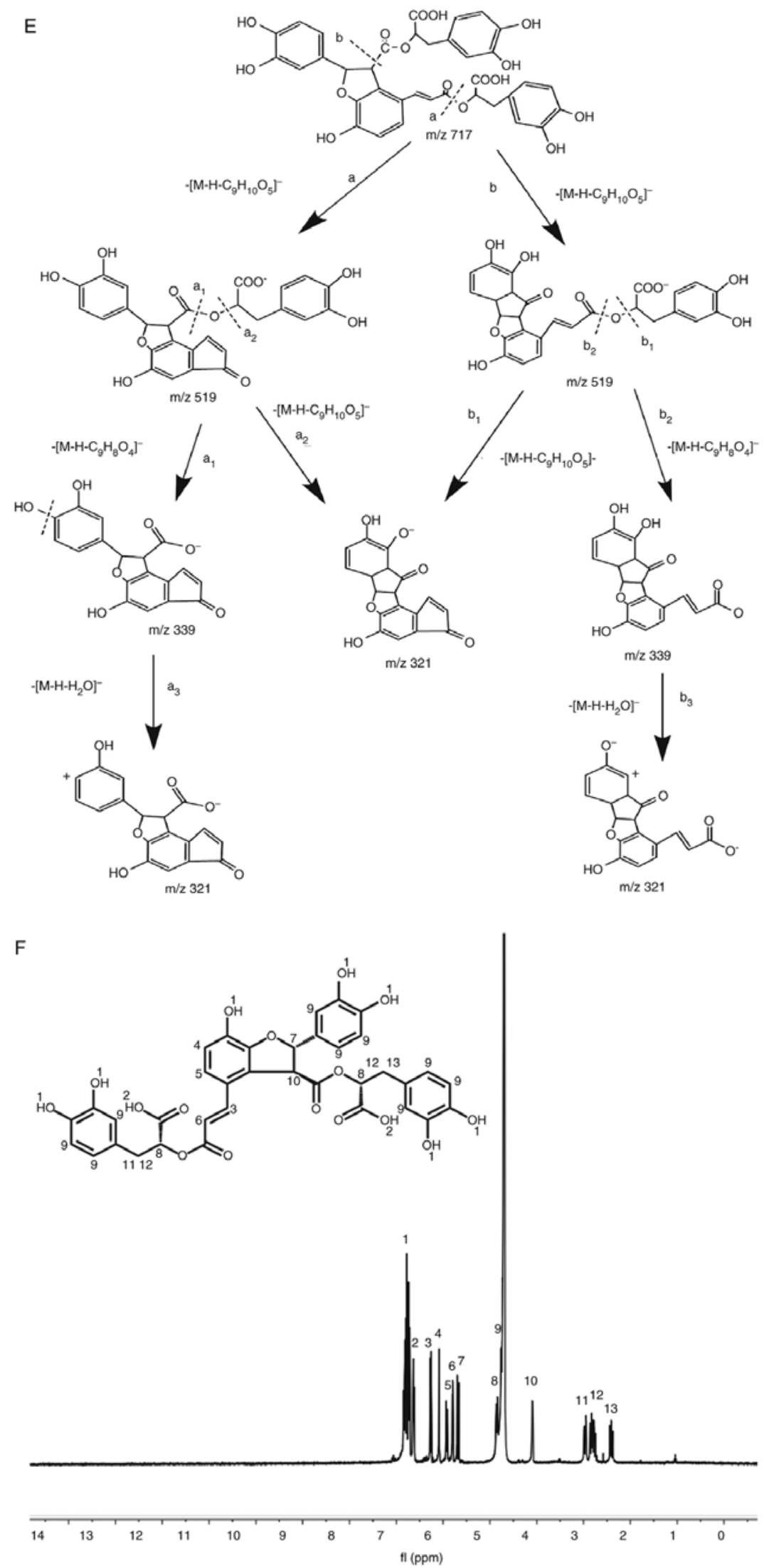

Figure 2. Continued. Sal-B identification via liquid chromatography-mass spectrometry, LC-MS ${ }^{2}$ and ${ }^{1} \mathrm{H}$ NMR spectrum. (E) Proposed ESI-MS ${ }^{2}$ fragmentation pathway of Sal-B. (F) ${ }^{1} \mathrm{H}$ NMR spectrum of Sal-B $\left(\mathrm{D}_{2} \mathrm{O}\right)$. LC-MS ${ }^{2}$, liquid chromatography-tandem mass spectrometry; NMR, nuclear magnetic resonance; ESI, electrospray ionization; Sal-B, salvianolic acid B.

S. bowleyana Dunn roots was significantly higher than that from S. miltiorrhiza Bge roots. The current extraction method was therefore improved and relatively simplified compared with previous methods $(37,38)$. 
A

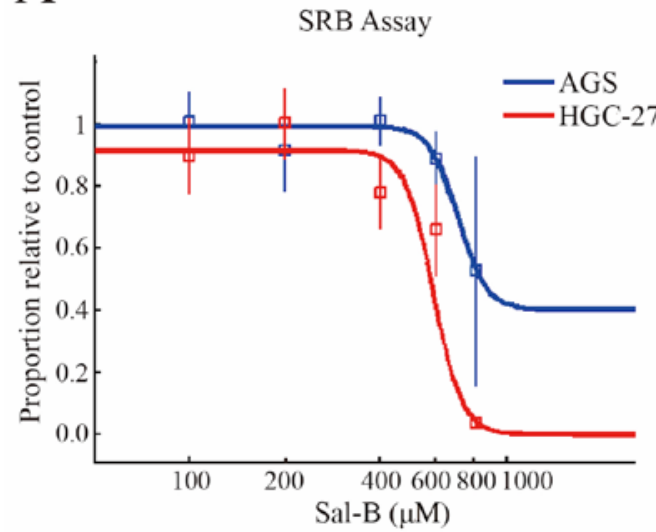

B

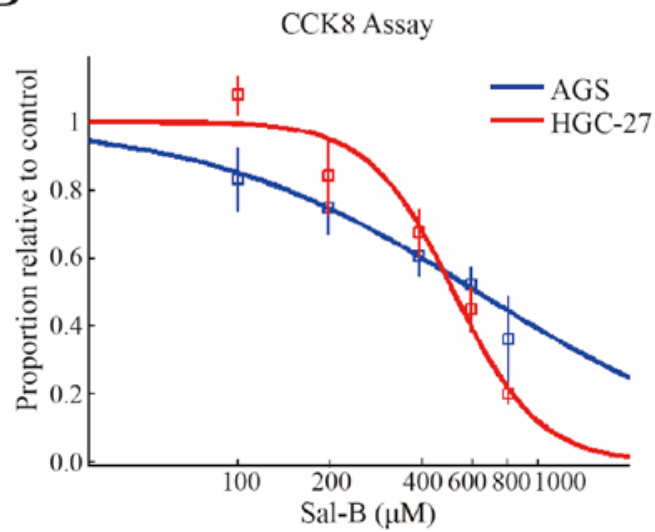

Figure 3. Sal-B suppresses gastric cancer cell growth in vitro. Cell proliferation was assessed by (A) SRB and (B) CCK-8 assays. Percentage cell viability was compared with parallel untreated cells. Data are shown as the mean \pm SEM $(n=3)$. Sal-B, salvianolic acid B; SRB, sulforhodamine B.

A
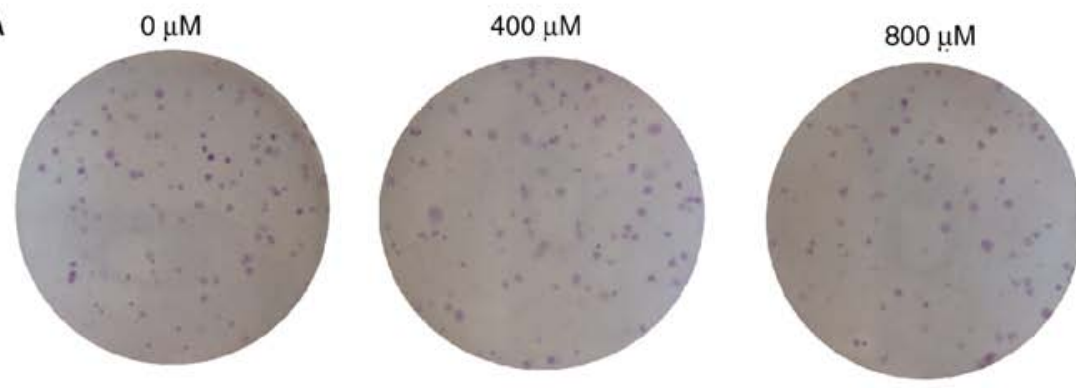

B

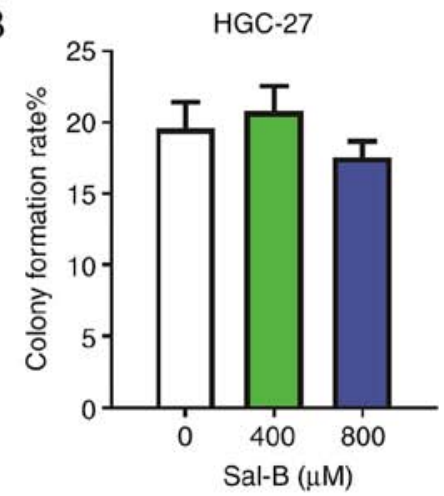

C
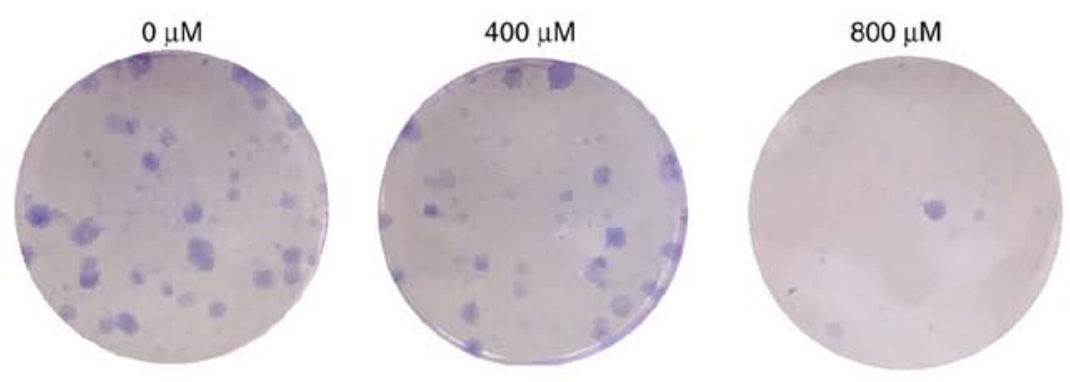

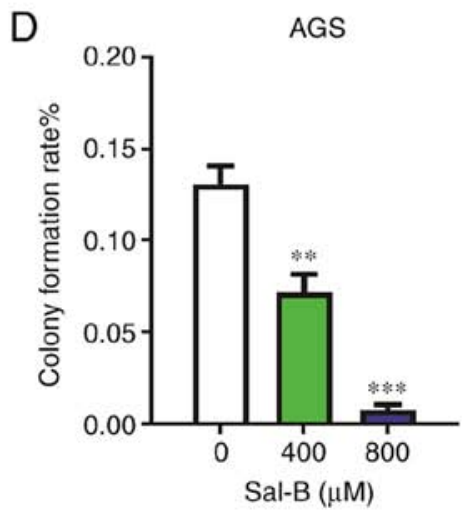

Figure 4. Effect of Sal-B on colony formation in gastric cancer cells. (A) Representative images and (B) quantification of colony forming assays in HGC-27 cells with or without Sal-B treatment. (C) Representative images and (D) quantification of colony forming assays in AGS cells with or without Sal-B treatment. Data are shown as the mean $\pm \operatorname{SEM}(\mathrm{n}=3) .{ }^{* *} \mathrm{P}<0.01 ;{ }^{* * *} \mathrm{P}<0.001$ vs. $0 \mu \mathrm{M}$ Sal-B. Sal-B, salvianolic acid $\mathrm{B}$. The images were captured using a Canon camera (EOS 70D).

S. bowleyana Dunn is widely distributed in the Fujian province, where there is a high incidence of gastric cancer (39). The extraction of compounds from S. bowleyana Dunn and the potential identification of anti-gastric cancer activities may result in a beneficial use of the plant in this region. The findings of the present study add substantial knowledge to the few reports regarding the anti-gastric cancer effects of Sal-B (40-43). In the current study, Sal-B extracted from $S$. bowleyana Dunn had an inhibitory effect on the proliferation of AGS and HGC cells. The ability of AGS cells to form colonies was strongly inhibited when cells were treated with high concentrations of Sal-B, while no significant inhibition was observed in HGC-27 cells. In addition, no significant differences were observed in the apoptotic marker cleaved caspase-3 when AGS and HGC-27 cells were treated with different concentrations of Sal-B. Although there was a significant difference in apoptosis between the control group and HGC-27 cells treated with 

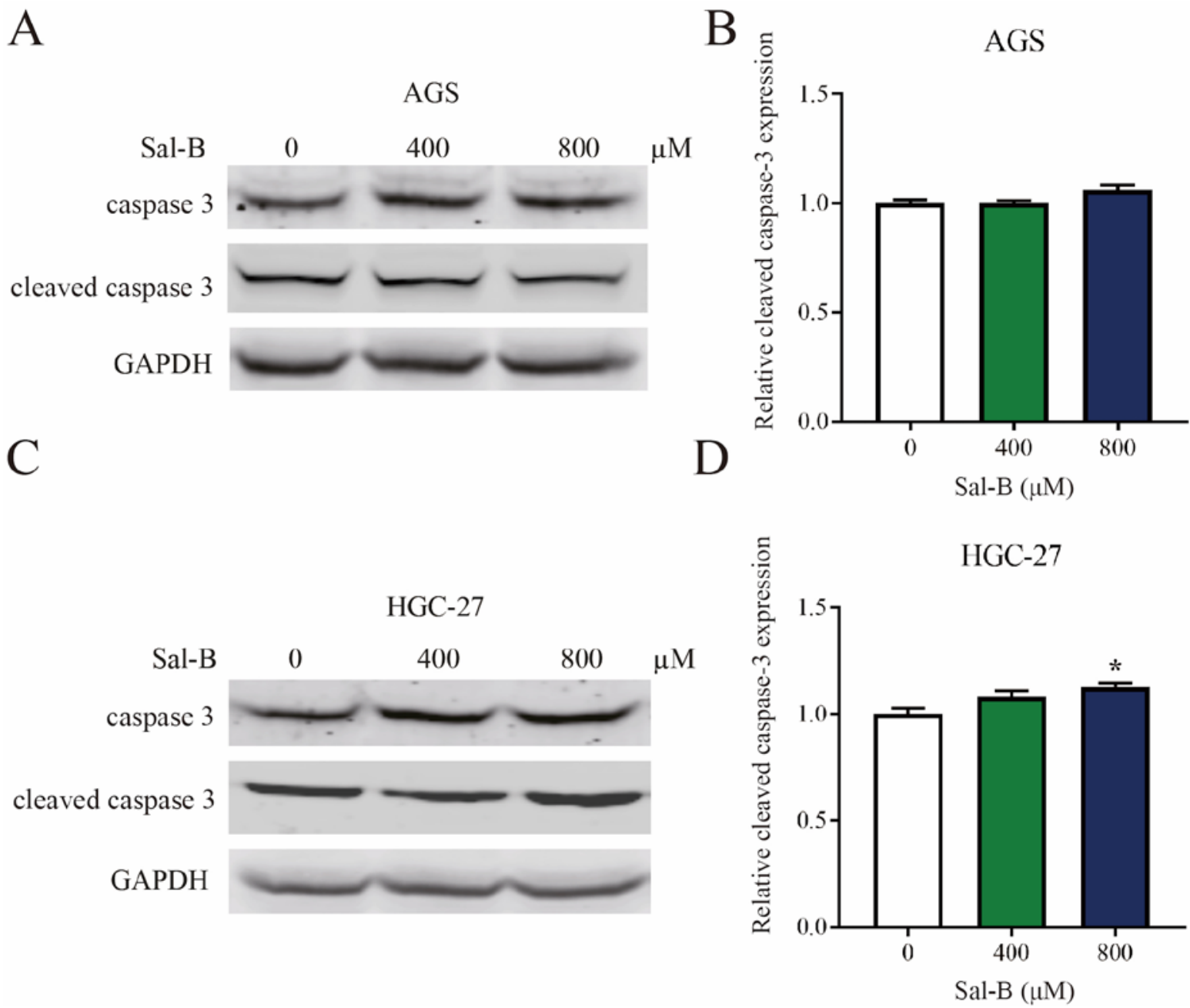

Figure 5. Effect of Sal-B on the apoptosis of gastric cancer cells. AGS and HGC-27 cells were exposed to Sal-B at concentrations of 0,400 and $800 \mu \mathrm{M}$ for $48 \mathrm{~h}$. Expression levels of cleaved caspase-3 were evaluated by western blotting. (A) Representative western blot images and (B) semi-quantification of cleaved caspase-3 in AGS cells. (C) Representative western blot images and (D) semi-quantification of cleaved caspase-3 in HGC-27 cells. Additionally, the rate of apoptosis in AGS and HGC-27 cells was assessed by flow cytometry. Data are shown as the mean \pm SEM $(\mathrm{n}=3)$. " $\mathrm{P}<0.05$ vs. $0 \mu \mathrm{M}$ Sal-B. Sal-B, salvianolic acid B; PI, propidium iodide.

$800 \mu \mathrm{M}$ Sal-B, the number of apoptotic cells was low. Sal-B may inhibit apoptosis by decreasing oxidative damage to mitochondrial DNA and protecting mitochondrial function. Additionally, Sal-B has been demonstrated to decrease the release of cytochrome $c$ from mitochondrial cells into the cytosol, thus inhibiting activated caspase-3 (44). However, in the present study Sal-B inhibited the proliferation of AGS and HGC-27 cells, suggesting that they may be directly killed. Sal-B is easily degraded within a few hours of exposure to an alkaline solution, which may be one of the causes of this phenomenon (45-47). Furthermore, different tumor cells have different levels of resistance to the same reagent; therefore, the development and assessment of stable Sal-B (alone or in combination with other drugs) may open more frontiers on its application. Further analyses to unravel the underlying mechanism of action for the inhibition of proliferation should be performed in future research.

Overall, the findings of the present study revealed that S. bowleyana Dunn contains a higher Sal-B content than $S$. miltiorrhiza Bge, and that it may be a novel source of this potentially anti-gastric cancer compound.

\section{Acknowledgements}

Not applicable.

\section{Funding}

The present study was supported by the International S\&T Cooperation Program of China (grant no. 2016YFE0121900), the Scientific Research Innovation Team Construction Program of Fujian Normal University (grant no. IRTL1702), the United Fujian Provincial Health and Education Project for Tackling the Key Research (grant no. WKJ2016-2-27), the Natural Science Foundation of Fujian Province (grant no. 2016Y0029) and the National Special Fund for Chinese medicine resources Research in the Public Interest of China (grant no. 2018-43).

\section{Availability of data and materials}

The datasets used and/or analyzed during the current study are available from the corresponding author upon reasonable request. 
E

Con

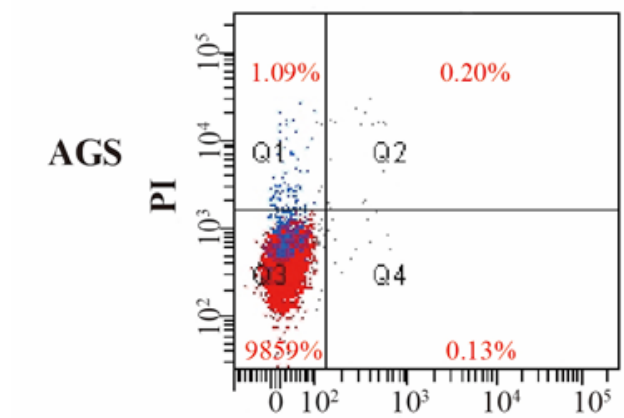

F

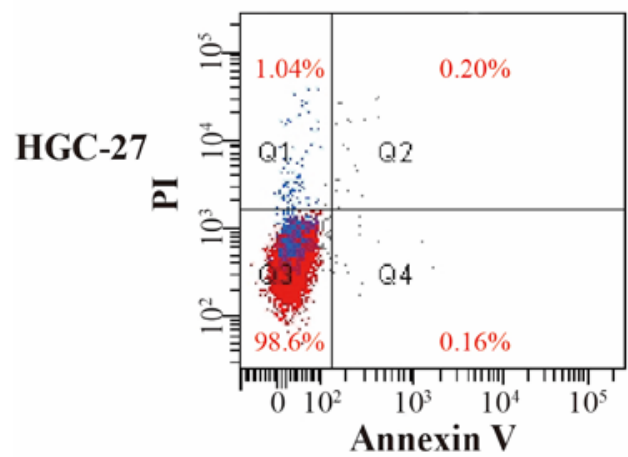

$400 \mu \mathrm{M}$

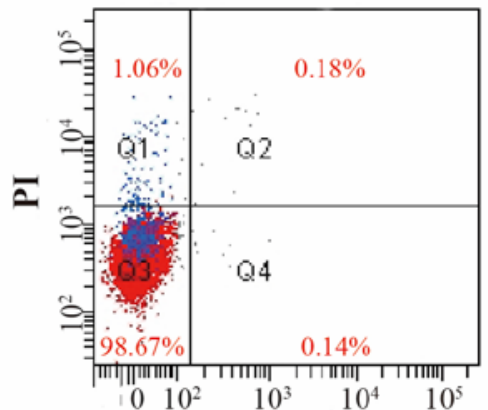

Annexin V

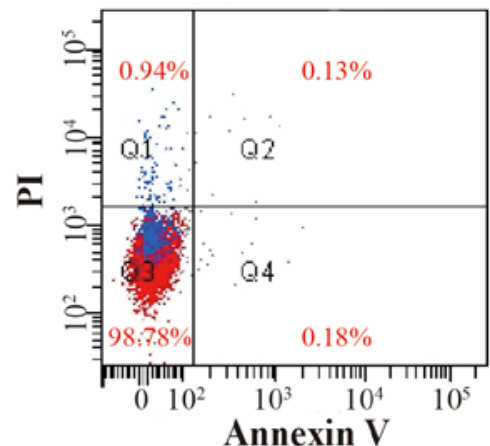

$800 \mu \mathrm{M}$

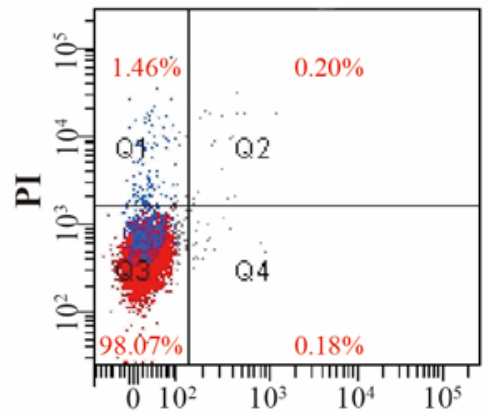

Annexin V

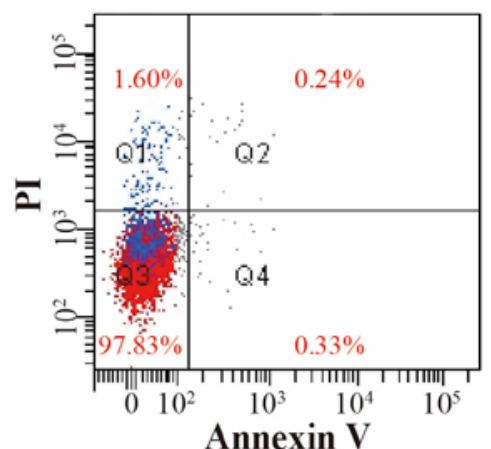

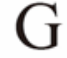

AGS

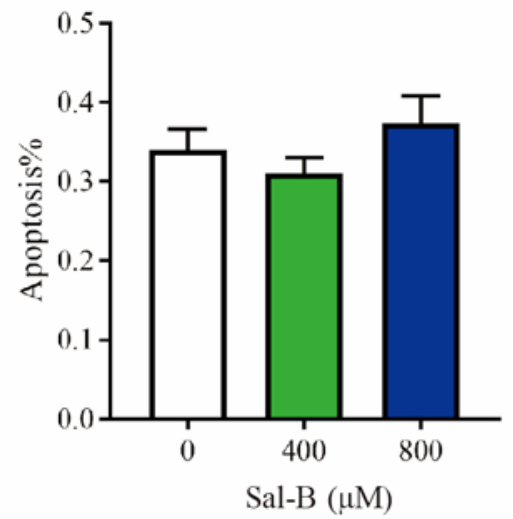

$\mathrm{H}$
HGC-27

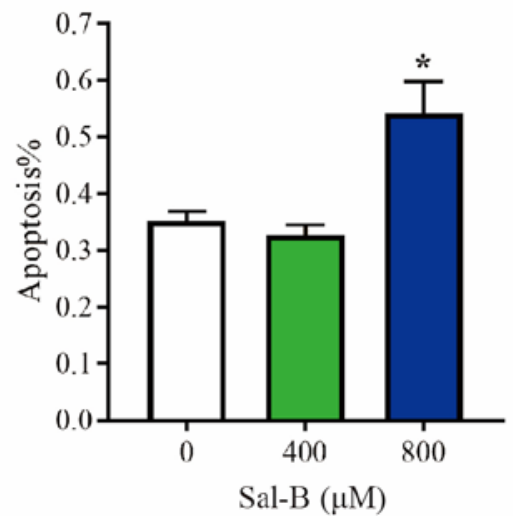

Figure 5. Continued. Effect of Sal-B on the apoptosis of gastric cancer cells. AGS and HGC-27 cells were exposed to Sal-B at concentrations of 0,400 and $800 \mu \mathrm{M}$ for $48 \mathrm{~h}$. Expression levels of cleaved caspase-3 were evaluated by western blotting. Representative scatterplots are provided for (E) AGS and (F) HGC-27 cells, and quantification of apoptosis in (G) AGS and (H) HGC-27 cells. Data are shown as the mean \pm SEM ( $\mathrm{n}=3$ ). ${ }^{*} \mathrm{P}<0.05$ vs. $0 \mu \mathrm{M}$ Sal-B. Sal-B, salvianolic acid B; PI, propidium iodide.

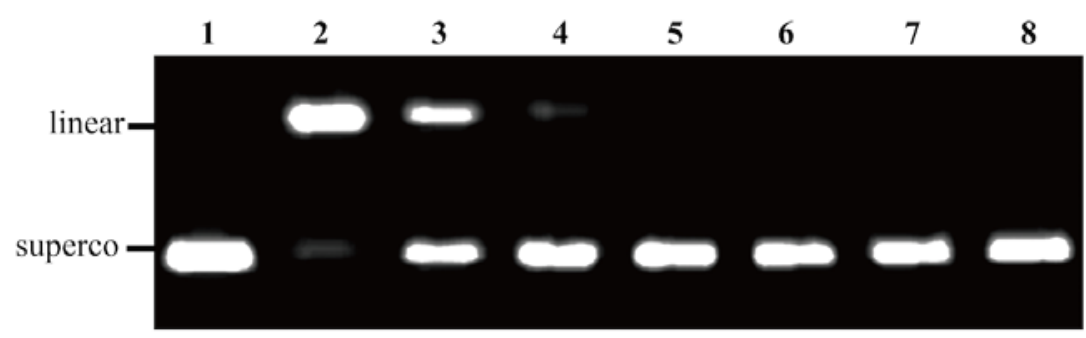

Figure 6. Protective effects of Sal-B from Salvia bowleyana Dunn on oxidative DNA damage induced by AAPH. Lane 1, native DNA; lane 2, DNA treated with AAPH and solvent; lane 3, DNA treated with AAPH and 0.004 mmol/1 Sal-B; lane 4-7, DNA treated with AAPH and 0.017, $0.03,0.06$ and 0.13 mmol/1 Sal-B, respectively; lane 8, DNA treated with AAPH and $0.08 \mathrm{mmol} / 1$ rutin. A total of $100 \mathrm{ng}$ pUC18 DNA and $12.5 \mathrm{mmol} / 1 \mathrm{AAPH}$ were used in every appropriate lane. Sal-B, salvianolic acid B; AAPH, 2,2'-azobis (2-methylpropionamidine) dihydrochloride; superco, supercoiled. 


\section{Authors' contributions}

$\mathrm{BC}$ designed and performed the experiments, and prepared the figures. $\mathrm{CH}$ designed and performed the experiments, drafted the initial manuscript, and prepared the figures. YZ extracted Sal-B and performed partial verification experiments. XT, SL and QW performed the experiments and analyzed the data. YL conceived and designed the experiments and drafted the initial manuscript. All authors read and approved the final manuscript.

\section{Ethics approval and consent to participate}

Not applicable.

\section{Patient consent for publication}

Not applicable.

\section{Competing interests}

The authors declare that they have no competing interests.

\section{References}

1. Lee HJ, Seo M and Lee EJ: Salvianolic acid B inhibits atherogenesis of vascular cells through induction of Nrf2-dependent heme oxygenase-1. Curr Med Chem 21: 3095-3106, 2014.

2. Guan Y, Zhu JP, Shen J, Jia YL, Jin YC, Dong XW and Xie QM: Salvianolic acid B improves airway hyperresponsiveness by inhibiting MUC5AC overproduction associated with Erk1/2/P38 signaling. Eur J Pharmacol 824: 30-39, 2018.

3. Fan ZK, Lv G, Wang YF, Li G, Yu DS, Wang YS, Zhang YQ, Mei XF and Cao Y: The protective effect of salvianolic acid B on blood-spinal cord barrier after compression spinal cord injury in rats. J Mol Neurosci 51: 986-993, 2013.

4. Wu Z, Li JN, Bai ZQ and Lin X: Antagonism by salvianolic acid $\mathrm{B}$ of lipopolysaccharide-induced disseminated intravascular coagulation in rabbits. Clin Exp Pharmacol Physiol 41: 502-508, 2014.

5. Hao Y, Xie T, Korotcov A, Zhou Y, Pang X, Shan L, Ji H, Sridhar R, Wang P, Califano J and Gu X: Salvianolic acid B inhibits growth of head and neck squamous cell carcinoma in vitro and in vivo via cyclooxygenase- 2 and apoptotic pathways. Int J Cancer 124: 2200-2209, 2009.

6. Wang ZS, Luo P, Dai SH, Liu ZB, Zheng XR and Chen T: Salvianolic acid B induces apoptosis in human glioma U87 cells through p38-mediated ROS generation. Cell Mol Neurobiol 33: 921-928, 2013.

7. Li HB, Lai JP, Jiang Y and Chen F: Preparative isolation and purification of salvianolic acid B from the Chinese medicinal plant Salvia miltiorrhiza by high-speed counter-current chromatography. J Chromatogr A 943: 235-239, 2002.

8. Zhi W and Deng Q: Purification of salvianolic acid B from the crude extract of Salvia miltiorrhiza with hydrophilic organic/salt-containing aqueous two-phase system by counter-current chromatography. J Chromatogr A 1116: 149-152, 2006.

9. Sun Y, Zhu H, Wang J, Liu Z and Bi J: Isolation and purification of salvianolic acid A and salvianolic acid B from Salvia miltiorrhiza by high-speed counter-current chromatography and comparison of their antioxidant activity. J Chromatogr B Analyt Technol Biomed Life Sci 877: 733-737, 2009.

10. Kuang H, Wang Y, Hu J, Wang C, Lu S and Mo X: A method for preparation of an internal layer of artificial vascular graft co-modified with Salvianolic acid B and heparin. Acs Appl Mater Interfaces 10: 19365-19372, 2018.

11. Shang Q, Xu H and Huang L: Tanshinone IIA: A promising natural cardioprotective agent. Evid Based Complement Alternat Med 2012: 716459, 2012.
12. Wu DM, Wang YJ, Han XR, Wen X, Li L, Xu L, Lu J and Zheng YL: Tanshinone IIA prevents left ventricular remodelling via the TLR4/MyD88/NF- $\mathrm{KB}$ signalling pathway in rats with myocardial infarction. J Cell Mol Med 22: 3058-3072, 2018.

13. Wang XX, Yang JX, Pan YY and Zhang YF. Protective effects of tanshinone IIA on endothelial progenitor cells injured by tumor necrosis factor- $\alpha$. Mol Med Rep 12: 4055-4062, 2015.

14. Xue Y, Yan J and Feng J: Treatment with tanshinone IIA suppresses disruption of the blood-brain barrier and reduces expression of adhesion molecules and chemokines in experimental autoimmune encephalomyelitis. Eur J Pharmacol 771: 18-28, 2016.

15. Gao H, Liu X, Sun W, Kang N, Liu Y, Yang S, Xu QM, Wang C and Chen X: Total tanshinones exhibits anti-inflammatory effects through blocking TLR4 dimerization via the MyD88 pathway. Cell Death Dis 8: e3004, 2017.

16. Gao S,LiuZ,LiH,Little PJ,Liu Pand Xu S: Cardiovascular actions and therapeutic potential of tanshinone IIA. Atherosclerosis 220: $3-10,2012$.

17. Fang J, Little PJ and Xu S: Atheroprotective effects and molecular targets of tanshinones derived from herbal medicine danshen. Med Res Rev 38: 201-228, 2017.

18. Hou J, He J, Jin X, Hu T and Zhang Y: Study on optimisation of extraction process of tanshinone IIA and its mechanism of induction of gastric cancer SGC7901 cell apoptosis. Afr J Tradit Complement Altern Med 10: 456-458, 2013.

19. Wang JB, Wang ZW, Li Y, Huang CQ, Zheng CH, Li P, Xie JW, Lin JX, Lu J, Chen QY, et al: CDK5RAP3 acts as a tumor suppressor in gastric cancer through inhibition of $\beta$-catenin signaling. Cancer Lett 385: 188-197, 2017.

20. Tao L, Wang S, Zhao Y, Sheng X, Wang A, Zheng S and Lu Y. Phenolcarboxylic acids from medicinal herbs exert anticancer effects through disruption of COX-2 activity. Phytomedicine 21: 1473-1482, 2014

21. Chen GY, Shu YC, Chuang DY and Wang YC: Inflammatory and apoptotic regulatory activity of tanshinone IIA in helicobacter pylori-infected cells. Am J Chin Med 44: 1187-1206, 2016.

22. Chen CY, Li H, Yuan YN, Dai HQ and Yang B: Antioxidant activity and components of a traditional Chinese medicine formula consisting of Crataegus pinnatifida and Salvia miltiorrhiza. BMC Complement Altern Med 13: 99, 2013.

23. Wang K, Yang Q, Ma Q, Wang B, Wan Z, Chen M and Wu L: Protective effects of salvianolic acid a against dextran sodium sulfate-induced acute colitis in rats. Nutrients 10: E791, 2018

24. Pasakova I, Klimes J, Sochor J and Hrabalek A: Optimization of HPLC chromatographic conditions for determination of Transkarbam 12 and its degradation products. J Pharm Biomed Anal 42: 136-142, 2006.

25. Luo Q, Wang D, Wei Z and Wang Z: Optimized chromatographic conditions for separation of halogenated acetic acids by ultra-performance liquid chromatography-electrospray ionization-mass spectrometry. J Chromatogr A 1277: 26-34, 2013.

26. Demiralay EC: An experimental design approach to optimization of the liquid chromatographic separation conditions for the determination of metformin and glibenclamide in pharmaceutical formulation. Acta Chim Slov 59: 307-314, 2012.

27. Jones-Lepp TL and Momplaisir GM: New applications of LC-MS and LC-MS ${ }^{2}$ toward understanding the environmental fate of organometallics. Trac-Trend Anal Chem 24: 590-595, 2005.

28. Wang Z, Cao B, Yu A, Zhang H and Qiu F: Ultrasound-assisted ionic liquid-based homogeneous liquid-liquid microextraction high-performance liquid chromatography for determination of tanshinones in Salvia miltiorrhiza Bge root. J Pharm Biomed Anal 104: 97-104, 2015.

29. Skehan P, Storeng R, Scudiero D, Monks A, McMahon J, Vistica D, Warren JT, Bokesch H, Kenney S and Boyd MR: New colorimetric cytotoxicity assay for anticancer-drug screening. J Natl Cancer Inst 82: 1107-1112, 1990.

30. Woolston C and Martin S: Analysis of tumor and endothelial cell viability and survival using sulforhodamine B and clonogenic assays. Methods Mol Biol 740: 45-56, 2011.

31. Fricker SP: The application of sulforhodamine B as a colorimetric endpoint in a cytotoxicity assay. Toxicol In Vitro 8: 821-822, 1994.

32. Zhang P and Omaye ST: DNA strand breakage and oxygen tension: Effects of beta-carotene, alpha-tocopherol and ascorbic acid. Food Chem Toxicol 39: 239-246, 2001.

33. Hu QP, Cao XM, Hao DL and Zhang LL: Chemical composition, antioxidant, DNA damage protective, cytotoxic and antibacterial activities of cyperus rotundus rhizomes essential oil against foodborne pathogens. Sci Rep 7: 45231, 2017. 
34. Lin Y, Richards FM, Krippendorff BF, Bramhall JL, Harrington JA, Bapiro TE, Robertson A, Zheleva D and Jodrell DI: Paclitaxel and CYC3, an aurora kinase A inhibitor, synergise in pancreatic cancer cells but not bone marrow precursor cells. Br J Cancer 107: 1692-1701, 2012.

35. Di Veroli GY, Fornari C, Goldlust I, Mills G, Koh SB, Bramhall JL, Richards FM and Jodrell DI: An automated fitting procedure and software for dose-response curves with multiphasic features. Sci Rep 5: 14701, 2015.

36. Zeng G, Xiao H, Liu J and Liang X: Identification of phenolic constituents in Radix Salvia miltiorrhizae by liquid chromatography/electrospray ionization mass spectrometry. Rapid Commun Mass Spectrom 20: 499-506, 2006.

37. Zhang Y, Xiao S, Sun L, Ge Z, Fang F, Zhang W, Wang Y and Cheng Y: Rapid screening of bioactive compounds from natural products by integrating 5-channel parallel chromatography coupled with on-line mass spectrometry and microplate based assays. Anal Chim Acta 777: 49-56, 2013

38. Wang X, Morris-Natschke SL and Lee KH: New developments in the chemistry and biology of the bioactive constituents of Tanshen. Med Res Rev 27: 133-148, 2007.

39. Wong BC, Lam SK, Wong WM, Chen JS, Zheng TT, Feng RE, Lai KC, Hu WH, Yuen ST, Leung SY, et al: Helicobacter pylori eradication to prevent gastric cancer in a high-risk region of China: A randomized controlled trial. JAMA 291: 187-194, 2004.

40. Zheng X, Chen S, Yang Q, Cai J, Zhang W, You H, Xing J and Dong Y: Salvianolic acid A reverses the paclitaxel resistance and inhibits the migration and invasion abilities of human breast cancer cells by inactivating transgelin 2. Cancer Biol Ther 16: $1407-1414,2015$

41. Wang QL, Wu Q, Tao YY, Liu CH and El-Nezami H: Salvianolic acid $\mathrm{B}$ modulates the expression of drug-metabolizing enzymes in HepG2 cells. Hepatobiliary Pancreat Dis Int 10: 502-508, 2011.
42. Li H, Shi L, Wei J, Zhang C, Zhou Z, Wu L and Liu W: Cellular uptake and anticancer activity of salvianolic acid B phospholipid complex loaded nanoparticles in head and neck cancer and precancer cells. Colloids Surf B Biointerfaces 147: 65-72, 2016.

43. Hao Y, Zhou Y, Ji H, Fang Y, Pang X, Southerland W, Califano J and $\mathrm{Gu} \mathrm{X}$ : Salvianolic acid B specifically inhibits cyclooxygenase-2 in human carcinoma cell lines in vitro and in vivo. Cancer Res 68: 2008.

44. Yan X, Zhou T, Tao Y, Wang Q, Liu P and Liu C: Salvianolic acid $\mathrm{B}$ attenuates hepatocyte apoptosis by regulating mediators in death receptor and mitochondrial pathways. Exp Biol Med (Maywood) 235: 623-632, 2010.

45. Li H, Wang S, Xie Y, Zhang B, Wang J, Yang Q and Cao W: Simultaneous determination of danshensu, salvianolic acid B, and paeonol in ShuangDan oral liquid by HPLC. J AOAC Int 96: 20-23, 2013.

46. Xintian Z and Haibin Q: Characterisation of the degradation of salvianolic acid B using an on-line spectroscopic analysis system and multivariate curve resolution. Phytochem Anal 23: 103-109, 2012.

47. Luo L, Yang B, Zhang G, Zhu W, Liu Y, Wei X, Kang X and Qu Z: Degradation kinetics of chlorogenic acid in honeysuckle during modified atmosphere heat pump drying. Int J Agric \& Biol Eng 9: 159-168, 2016.

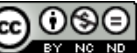

This work is licensed under a Creative Commons Attribution-NonCommercial-NoDerivatives 4.0 International (CC BY-NC-ND 4.0) License. 